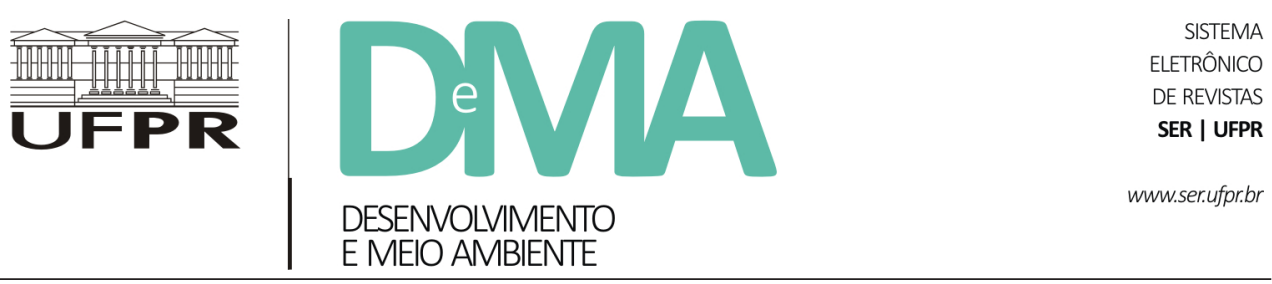

\title{
Sistema de governança em Unidades de Conservação
}

\section{Governance System in Protected Areas}

\author{
Gisele Rosa ABRAHÃO ${ }^{1 *}$, Milton ASMUS ${ }^{2}$ \\ ${ }^{1}$ Pós-Graduação em Geografia, Universidade Federal de Santa Catarina (UFSC), Florianópolis, SC, Brasil. \\ ${ }^{2}$ Universidade Federal de Rio Grande (FURG), Rio Grande, RS, Brasil. \\ *E-mail de contato: gisele.rosa.abrahao@gmail.com
}

Artigo recebido em 31 de agosto de 2017, versão final aceita em 26 de novembro de 2017.

RESUMO: $\quad$ Este artigo analisou o sistema da governança em Unidades de Conservação (UC). No sentido de aportar a necessária análise da governança para UCs, tomando em conta seus elementos de maior expressão, o presente trabalho teve como objetivo a identificação e a avaliação do sistema de governança de UCs com foco em seus componentes relacionados à educação ambiental, à gestão e à estrutura local. As UCs são fundamentais no processo de proteção das áreas naturais e na preservação dos serviços ecossistêmicos. No entanto, apresentam, em geral, problemas de governança. Estes problemas podem estar relacionados à falta de uma boa gestão e de uma estrutura adequada, ou ainda a uma educação ambiental deficiente. Para o desenvolvimento deste trabalho, optou-se por um estudo de caso, envolvendo a Estação Ecológica de Carijós (ESEC Carijós) em Florianópolis, SC/Brasil, dominada por ecossistemas de manguezais e áreas remanescentes de restinga. Os resultados desta pesquisa demostram que, para uma boa governança, é necessário levar em consideração a escolha do gestor, estando atento ao perfil do mesmo em relação à realidade local. Também conclui-se que o conselho gestor é uma ferramenta fundamental de gestão participativa e na busca por resultados mais promissores, com atenção às necessidades da comunidade, aliada à conservação dos recursos naturais. A educação ambiental e a participação comunitária, da mesma maneira, são premissas importantes para o processo de gestão de uma UC, sendo fundamentais para o resultado do trabalho realizado. Por fim, a participação do terceiro setor se mostra como um caminho importante para suprir as demandas que surgem nestes espaços e que não conseguem ser supridas pelo órgão gestor das UCs.

Palavras-chave: Unidades de Conservação; governança; educação ambiental; gestão participativa.

ABSTRACT: This article analyzed the system of governance in protected areas (PA). In order to provide the necessary governance analysis for PAs, taking into account its major features, the present work aimed the identification and evaluation of PAs governance system focusing on its components related to the environmental education, 
management and local structure. PAs are fundamental in the process of protecting natural areas and for the preservation of ecosystem services. However, PAs commonly present governance difficulties. These problems may be related to the lack of good management and adequate structure, or even due to poor environmental education. As a case study Carijós Ecological Station (ESEC Carijós) in Florianopolis, SC / Brazil was chosen, constituted by mangroves and remaining areas of salt marsh and scrubland. The results of this research showed that in order to have good governance it is necessary to take into account the manager's choice, being attentive to the manager profile in relation to the local reality. It is also concluded that the management council, formed by different stakeholders, is a fundamental tool for participatory management and more promising results. It combines the needs of the community with the conservation of natural resources. Environmental education and community participation, in the same way, are an important premise for the management process of a PA, and are fundamental to the results of the work carried out. Finally, the participation of non-government organizations is shown as an important way to meet the demands that arise in these spaces and which cannot be provided by the government manager of the PAs.

Keywords: Protected Areas; governance; environmental education; participatory management.

\section{Introdução}

Esse artigo analisa o sistema da governança em Unidades de Conservação (UC), tendo como foco os pontos fundamentais para a sua boa funcionalidade. O Brasil se destaca entre os países com maior diversidade de vida no planeta (IBAMA, 2001). Muitas destas áreas importantes estão inseridas em UC, sendo esta uma estratégia para a proteção da biodiversidade (Dick et al., 2012). No entanto, a falta de uma participação mais efetiva da população e a ausência de uma boa governança têm sido grandes desafios desde o início da criação das primeiras UCs no Brasil no final da década de 1930, dificultando a implementação, de fato, destas unidades de conservação (Caruso, 1990; Tozzo \& Marchi, 2014).

As UCs no Brasil, em sua grande maioria, possuem problemas de governança. Estes problemas podem estar representados pela ausência de fatores relacionados com uma gestão adequada, que incluem instrumentos de suporte e sua base legal e política, tais como zona de amortecimento, ordenamento territorial, plano de manejo realizado pelo órgão competente com participação efetiva dos atores interessados no processo, conselho gestor, entre outros. Uma estrutura adequada (física e humana) para o bom funcionamento das UCs demandaria investimento e sustentabilidade efetiva, necessários para uma boa gestão (Pomeroy et al., 2004; Mccay \& Jones, 2011; Jones et al., 2013). Finalmente, observa-se a deficiência de uma efetiva educação ambiental capaz de fortalecer, sensibilizar e trazer informações pertinentes, no sentido de pertencimento aos atores envolvidos e sua participação nos processos de tomada de decisões nas Unidades de Conservação (Mccay \& Jones, 2011; Dick et al., 2012, Barragán, 2014).

Há muitos conceitos diferentes em relação ao tema governança (Borrini-Feyerabend, 2003; Nguinguiri, 2003; Puz et al., 2003). Neste trabalho, assume-se o conceito de uma Governança Ambiental Sistêmica como um sistema complexo de interações entre estruturas, educação ambiental e gestão participativa, onde decisões de interesse público são tomadas com a participação da sociedade no processo. Nesse sentido, uma boa governança pode 
ser interpretada como uma relação equilibrada entre Gestão, Estrutura e Educação Ambiental, podendo, assim, desempenhar sua função de conservação de áreas naturais a serem protegidas. Muitos autores têm discutido a importância do papel que as partes envolvidas (componentes da governança) desempenham para atingir o sucesso de Unidades de Conservação (Himes, 2007).

A educação ambiental é proposta aqui como um caminho de construção chave para a estruturação da gestão e da governança efetivas em UC. Barragán (2014) descreve os problemas resultantes das atividades de gestão em UCs sem a percepção sobre o humano e o meio em que está inserido. Não parece haver sucesso efetivo de planos de gestão se não houver uma participação real e efetiva de todos os atores envolvidos, inserindo as pessoas que vivem neste espaço e o conhecimento por elas adquirido no uso de uma área protegida (Fischer et al., 2006; Barragán, 2014). Embora existam obstáculos, iniciativas inovadoras e participativas podem fazer a diferença no auxílio à criação, ao planejamento, à implementação e à gestão de uma UC. Dentre elas, as ações de sensibilização, de capacitação e atividades que possam promover trocas de experiências entre diversos atores relacionadas às UCs, seus conselhos e demais pessoas envolvidas em um processo inclusivo de gestão (Dick et al., 2012).

Parece legítimo afirmar a importãncia de inserir a educação ambiental nos processos de tomadas de decisões que interessam à sociedade. É, no entanto, importante discutir a forma da inserção de pessoas neste processo e o tipo de educação ambiental que está sendo realizada. No sentido de aportar a necessária análise da governança para UCs, tomando em conta seus elementos de maior expressão, o presente trabalho teve como objetivo a identificação e a avaliação do sistema de governança de UCs com foco em seus componentes relacionados à educação ambiental, à gestão e à estrutura local. Para o seu desenvolvimento, optou-se por um estudo de caso, envolvendo a Estação Ecológica de Carijós (ESEC Carijós) em Florianópolis, Santa Catarina/Brasil, dominada por ecossistemas de manguezais e áreas remanescentes de restinga.

\section{2. Área de estudo}

A ESEC Carijós é um caso representativo em relação à situação de muitas UCs do Brasil por apresentar indícios de problemas de governança. Além disto, é significativa pelas características apresentadas a seguir, como sua localização em áreas costeiras, de grande relevância econômica e socioambiental, como restingas e manguezais, e que sofrem grande impacto pela ocupação humana. Localizada na região Noroeste Ilha de Florianópolis/ Santa Catarina, é uma Unidade de Conservação Federal criada pelo decreto $n^{\circ} 94.656$ de 1987 , tendo como objetivos a preservação da natureza e a realização de pesquisas científicas e atualmente é gerida pelo Instituto Chico Mendes de Conservação da Biodiversidade (ICMBio). Abrange em sua superfície uma área de 720 ha, sendo a gleba do Saco Grande de 95 ha e a de Ratones de 625 ha (IBAMA, 2001). O bioma local é de domínio Mata Atlântica, tendo como ecossistemas manguezais e restingas, onde foram identificadas mais de 500 espécies de animais e dezenas de espécies de flora de manguezal e restinga; da fauna podem ser destacados o jacaré-de-papo-amarelo, a lontra, o ratão-do-banhado e o graxaim (IBAMA, 2001). Estudos demonstram ainda que ocorrem na região 
110 espécies de aves. A fauna aquática também é rica, podendo ser citados caranguejo, mariscos, ostras, robalos, tainhas, bagres e camarões. A ESEC Carijós também protege três sítios arqueológicos, os sambaquis (IBAMA, 2001).

Grande parte dos manguezais na Ilha de Santa Catarina foi aterrada ou desmatada, incluindo os manguezais de Carijós, dos quais restaram apenas $38 \%$ da área original do manguezal de Ratones e $68 \%$ do manguezal do Saco Grande, sendo o manguezal de Ratones o mais preservado da Ilha de Santa Catarina (IBAMA, 2001) (Figura 1).

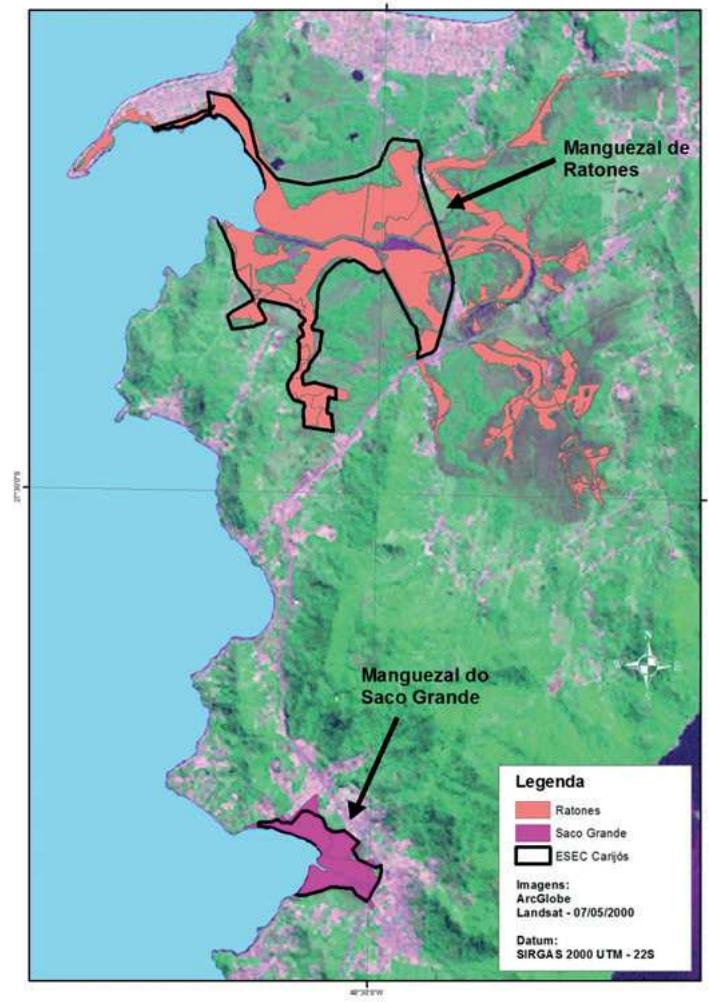

FIGURA 1 - Localização da Estação Ecológica de Carijós, Florianópolis, Santa Catarina, Brasil.

FONTE: Adaptação do mapa a partir dos arquivos dos limites da ESEC realizado para elaboração da revisão do Plano de Manejo da ESEC (ICMBio, 2010).
O nome Carijós é uma homenagem aos índios residentes na ilha na época da colonização. Importante fisar que, em qualquer ESEC é proibida a visitação pública, exceto com objetivo educacional, e a pesquisa científica depende de autorização prévia do órgão responsável (IBAMA, 2001; Junior et al., 2015).

\section{Material e métodos}

Para o desenvolvimento deste trabalho foram realizadas, além de pesquisa bibliográfica, entrevistas exploratórias individuais, qualitativas, semiestruturada, com representantes de atores-chave da ESEC Carijós. Para a definição dos atores, denominados aqui de informantes qualificados, levou-se em consideração o conhecimento e a relação do entrevistado com a área de estudo, a percepção quanto a fatos e/ou situações dentro do contexto histórico da ESEC Carijós e os temas-chave de interesse. Entrevistar atores-chave é de fundamental importância para o complemento da pesquisa científica, trazendo a percepção das pessoas em relação a um fato ou situação dentro do contexto apresentado (Minayo, 1999; Alberti, 2010).

Na escolha dos entrevistados, foram selecionados atores principalmente da lista de participantes das últimas reuniões do Conselho Gestor da ESEC Carijós - CONSECA, ocorridas entre os anos de 2011 e 2012. A partir desta lista, outros atores foram identificados, complementando o grupo a ser ouvido. Foram entrevistadas 19 pessoas, entre representantes do ICMBio relacionados com a ESEC Carijós (quatro representantes), órgão fiscalizador ambiental do município - FLORAN (um representante), ONG (seis representantes) e comunidade lo- 
cal (oito representantes). Os três principais gestores da ESEC Carijós desde sua criação também foram entrevistados, com destaque, sendo identificados ao longo do artigo como Gestor 1, Gestor 2 e Gestor 3 respectivamente. As perguntas foram organizadas de modo a nortear o tipo de informação que se propunha a fim de obter resultados sobre os temas propostos. Todas as entrevistas foram gravadas. Quanto ao entrevistado, foi destacado se o mesmo nasceu e reside na área de influência da ESEC Carijós (que compreende o município de Florianópolis e a Baía Norte da Ilha de Santa Catarina) (IBAMA, 2001). Estes dados são importantes para se ter uma base do perfil do entrevistado e sua relação com a área de estudo.

\section{Resultados}

Para análise dos resultados, todas as entrevistas foram transcritas e, em seguida, organizadas pelos principais tópicos a serem analisados, ou seja, estrutura, gestão e educação ambiental. Por fim, as informações foram organizadas em uma linha do tempo, desde a criação da ESEC Carijós em 1987, até 2016. Nesta linha do tempo, delimitaram-se quatro períodos marcantes: Pré-período (1987 1998), da criação da ESEC Carijós até sua primeira gestão; Primeiro período (1998 - 2002) - marcado pela primeira Gestão da ESEC Carijós; Segundo período (2004 - 2010) - segunda Gestão da ESEC Carijós; Terceiro período (2011 - 2016) - terceira Gestão da ESEC Carijós.

A Tabela 1 apresenta um resumo dos resultados apresentados a seguir.

\subsection{Pré-período (1987 - 1998) - Criação da ESEC Carijós}

A ideia de criar a ESEC Carijós surge em 1987, em função da necessidade de proteger remanescentes de manguezais na Ilha de Santa Catarina de futuras alterações por ações antrópicas, principalmente expansão urbana e especulação imobiliária (IBAMA, 2001). Esta afirmação demonstra com clareza o objetivo da criação da ESEC Carijós, uma realidade de grande parte da UCs do Brasil, que sempre foi a conservação de seus ambientes naturais. Também foi diagnosticado que houve falta de análise da percepção das comunidades que sempre ocuparam estes espaços, gerando conflitos que foram evidenciados pelos resultados. Destaca-se neste período a criação da UC e a proteção dos ecossistemas naturais, principalmente manguezais. O porquê de estar protegendo esta área é compreendido com clareza entre os entrevistados.

Ela é importante para a cidade, não só para a região. De alguma forma a Estação aqui dentro é um fator restritivo para o crescimento desordenado da cidade e até para a especulação imobiliária [...]. [...] Então a Estação é fundamental porque ela tem voz dentro da cidade. [...] (Entrevistado 16) ${ }^{1}$

\subsubsection{Estrutura}

Neste período da ESEC Carijós, pouca estrutura física e humana foi instalada e/ou mantida no local. Além de meios de transportes motorizados, como carros e motos (que acabaram sendo doados

\footnotetext{
${ }^{1} 52$ anos, masculino, não nascido, residente na área de influência da ESEC Carijós.
} 
para outras UCs), ocorreu a construção de uma casa no manguezal do Saco Grande, que deveria servir para a fiscalização, mas que nunca foi usada e acabou sendo demolida (IBAMA, 2001). Em 1981 foram demarcadas as áreas dos manguezais do Rio Ratones e Saco Grande, em 1983 foi efetuada a cessão destas áreas para a SEMA (Secretaria Especial de Meio Ambiente) e para a FATMA (Fundação do Meio Ambiente) e finalmente, em 1987, foi criada a ESEC Carijós (IBAMA, 2001).

\subsubsection{Gestão}

Não houve gestão pela FATMA durante este período e a UC, quando repassada para o IBAMA (Instituto Brasileiro do Meio Ambiente e dos Recursos Naturais Renováveis), recebeu gestões de chefes que eram responsáveis por várias UCs, sem atuação exclusiva na ESEC Carijós. A UC não possuía Plano de Manejo e nem uma equipe específica para este trabalho (IBAMA, 2001; Entrevistada 12). A única atuação direta foi de fiscalização, principalmente sobre a pesca, conforme relato dos entrevistados $2^{3}$ e $3^{4}$.

[...] Primeiro o pescador teve que sofrer, teve que receber arma na cara, ser preso, perder a embarcação, perder apetrecho de pesca, perdeu o local de pesca onde para nós é considerado o peixe adulto. Tá lá dentro da ESEC, deixando a parte que é berçário fora [...] (Entrevistado 2).

\subsubsection{Educação ambiental e participação comunitária}

Ações de educação ambiental e movimentos de participação comunitária tampouco foram registrados neste período. A criação da ESEC Carijós foi realizada por órgãos públicos, sem qualquer abordagem e/ou participação da comunidade do entorno da UC. Isto fica evidente na fala dos entrevistados $1,2,3,4^{5}, 8^{6}$ e $9^{7}$, com enfoque para os pescadores.

[...] eu vejo sentido na existência da ESEC Carijós. Não na forma de como ela foi criada. Porque quando ela foi criada foi simplesmente de cima para baixo, não viam as populações que moravam/dependiam deste rio, que trabalhavam neste rio. Isto não foi construído, foi construído muito depois, e a duras penas (Entrevistado 2).

\subsection{Primeiro período (1998 - 2002) - Primeira Gestão da ESEC Carijós}

O primeiro período é marcado pela chegada da primeira gestora designada para atuar diretamente na ESEC Carijós. A atuação da Gestora 1 na Unidade é fundamental para o desenvolvimento de um plano de manejo de forma participativa junto à comunidade.

\footnotetext{
252 anos, feminina, não nascida, residente na área de influência da ESEC Carijós.

${ }^{3} 52$ anos, masculino, nascido e residente na área de influência da ESEC Carijós.

${ }^{4} 54$ anos, masculino, nascido e residente na área de influência da ESEC Carijós.

${ }^{5} 39$ anos, feminina, não nascida, não residente na área de influência da ESEC Carijós.

${ }^{6} 43$ anos, feminina, não nascida, residente na área de influência da ESEC Carijós.

${ }^{7} 59$ anos, feminina, nascida e residente na área de influência da ESEC Carijós.
} 


\subsubsection{Estrutura}

A estrutura física encontrada era precária e com nenhuma mão de obra, sendo feitas melhorias no espaço físico. Dois carros foram cedidos pelo IBAMA e havia material administrativo básico (Entrevistada 1). Já em relação ao pessoal, além de três servidores públicos que foram solicitados, foi designado um grupo de estudantes e profissionais voluntários com formação na área ambiental para atuar junto à UC. Este grupo deu origem, em 1999, à Associação de Amigos Pró-Conservação da Estação Ecológica de Carijós - "Amigos de Carijós", que manteve esta estrutura até 2005 (Brasil, 1999; IBAMA, 2001; Entrevistada 4; Entrevistada 1).

\subsubsection{Gestão}

A Gestora 1 teve o desafio de inserir a comunidade de entorno nos processos de gestão da Unidade, entre eles o plano de manejo. $\mathrm{O}$ trabalho realizado é até hoje considerado pioneiro, fazendo com que a ESEC Carijós se tornasse modelo de gestão no Brasil. Há de se levar em consideração as discussões que ocorriam neste momento da história, em relação à percepção das comunidades que vivem no entorno das UCs não somente no Brasil, mas em todo o mundo, além do perfil social da Gestora, que muito contribuiu para seu olhar no entorno da Unidade. Sua atuação foi tão significativa que marcou a história da ESEC Carijós, incluindo a comunida- de, que teve acesso ao seu trabalho neste período (Entrevistados 1, 3, 4, 6 $6^{8}, 7^{9}, 8,9^{10}, 13^{11}, 16$ e $17^{12}$ ).

[...] Pelo perfil acadêmico, profissional e pessoal mesmo dela, ela tinha esta coisa assim de articulação, de mobilização social. Então ela direcionou a gestão muito mais para fora do que para dentro. Então assim, foi um período de grande mobilização, [...] era visivel que a ESEC Carijós tinha de se articular, inclusive para dirimir, reduzir conflitos existentes desde a sua criação com determinados segmentos, que foi fundamental. [...] (Entrevistada 7).

Em relação ao plano de manejo e à criação do conselho gestor, a entrevistada 1 registra que a ESEC Carijós foi a primeira UC do Brasil a implantar um conselho gestor. Sua iniciativa acontece antes mesmo de o SNUC (Sistema Nacional de Unidades de Conservação) ser instituído no Brasil, momento em que o conselho gestor se consolida como obrigatoriedade nas UCs.

\subsubsection{Educação ambiental e participação comunitária}

Este foi outro ponto forte desta gestão, traduzido pela participação comunitária na construção do plano de manejo e nas atividades de educação ambiental, com forte atuação da Associação "Amigos de Carijós". Os relatos em relação à Associação "Amigos de Carijós", posteriormente transformada em Instituto Carijós Pró-Conservação da Natureza -

\footnotetext{
${ }^{8} 37$ anos, feminina, não nascida, residente na área de influência da ESEC Carijós.

${ }^{9} 47$ anos, feminina, não nascida, residente na área de influência da ESEC Carijós.

${ }^{10} 59$ anos, feminina, nascida e residente na área de influência da ESEC Carijós.

${ }^{11} 57$ anos, masculino, não nascido, residente na área de influência da ESEC Carijós.

1239 anos, feminina, não nascida, residente na área de influência da ESEC Carijós.
} 
IC, aparecem em muitas falas, apontando este grupo como protagonista nas ações de educação ambiental e participação comunitária junto à comunidade de entorno da ESEC Carijós (Entrevistados 2, 3, $5^{13}$, $6,7,8,9,10,13,16$ e 17). Os relatos demostram esta visão dos entrevistados.

[...] o projeto Amigos de Carijós $^{14}$ ele trabalhava com as escolas do entorno, não só com a Bacia do Rio Ratones, mas também aqui do Saco Grande. [...]. Eu lembro que eles iam nas escolas. [...] palestravam, levavam os alunos para conhecer o mangue [...] (Entrevistado 10) $)^{15}$.

O IC ${ }^{16}$ nasceu em 1999. Foi criado para dar suporte à ESEC Carijós na implementação da Unidade. Ai nasceram projetos nas comunidades, projeto de EA, projeto de mobilização comunitária. Então em termos de pessoal, recursos humanos, acho que neste momento era suprido pala ONG né. Talvez financeiro também porque a ONG era o capitalizador de recursos para implementação destes projetos [...] (Entrevistado 6).

\subsection{Segundo periodo (2004 - 2010) - Segunda Gestão da ESEC Carijós}

O Gestor 2 assume a ESEC Carijós entre os anos de 2004 - 2010. Nota-se que há intervalo de dois anos entre o primeiro e o segundo períodos. Atribui-se aqui ao fato de que houve breves períodos de gestão neste intervalo por alguns gestores que não tiveram destaque nas entrevistas.

\subsubsection{Estrutura}

A estrutura desta gestão se destaca pelo aporte de recursos por meio de projetos submetidos via IC. O Gestor 2 coloca seu ponto de vista em relação a esta parceria.

\begin{abstract}
[...] o que vi de mais interessante foi a parceria que a gente teve com a ONG. Incialmente chamava Amigos de Carijós, depois Instituto Carijós. Começa antes de mim (1999) e perpetuou por muito tempo até eu sair. E realmente [...] a gente conseguiu ter uma perna não governamental, que de certa forma é visto de uma melhor forma, a gente conseguia recursos, projetos, FNMA, $P D A^{17}[\ldots]$ (Entrevistado 5).
\end{abstract}

Para o Gestor 2, a parceria público-privado foi importante durante sua gestão. Por não ser uma ação direta do estado, se torna menos onerosa e com resultados a curta e médio prazos. Além disso, a parceria permitia recursos financeiros e humanos para a continuidade das ações a serem executadas.

\subsubsection{Gestão}

O Gestor 2 apresenta um perfil técnico, voltado para a fiscalização e para o reordenamento do uso do solo. Sua gestão se destaca pela atuação junto ao Conselho Gestor da UC - CONSECA (sem destaque nos demais períodos), em função de seu envolvimento junto à comunidade no processo de

1339 anos, masculino, não nascido, residente na área de influência da ESEC Carijós.

${ }^{14}$ A entrevistada está se referindo à Associação "Amigos de Carijós".

${ }^{15} 42$ anos, masculino, nascido e residente na área de influência da ESEC Carijós.

${ }^{16}$ Neste período, este grupo era designado “Amigos de Carijós”. IC nasce em 2005.

${ }^{17}$ FNMA (Fundo Nacional de Meio Ambiente), PDA (Subprograma Projetos Demonstrativos, implementado pelo Ministério do Meio Ambiente no âmbito do Programa Piloto para a Proteção das Florestas Tropicais - PPG7). 
análise da construção de um estaleiro na região. $\mathrm{O}$ empreendimento não ocorre, e o movimento leva à exoneração do Gestor 2, gerando insatisfação tanto da comunidade interna como da comunidade do entorno da UC. Este momento do CONSECA é histórico e está na fala de grande parte dos entrevistados (Entrevistados 2, 3, 5, 6, 7, 9, 12 ${ }^{18}, 14^{19}, 15^{20}$, $\left.16,17 \mathrm{e} 18^{21}\right)$. Os relatos indicam a falta de paridade entre as instituições governamentais e a comunidade, já que as instituições públicas somadas tinham mais força que a comunidade, a pouca efetividade do mesmo, com exceção do momento do empreendimento na segunda gestão, além da exoneração do Gestor 2. A importância do Conselho também é citada pelos entrevistados como uma ferramenta fundamental para uma boa governança e o processo de gestão participativa, além da necessidade urgente de reativação do mesmo.

\subsubsection{Educação ambiental e participação comunitária}

As ações de educação ambiental junto à comunidade seguem sendo desenvolvidas pelo Instituto Carijós, com apoio do Gestor 2, mas sem muito envolvimento do mesmo. Em relação à participação comunitária, houve uma mudança significativa em comparação com o período anterior analisado, principalmente quando se fala da relação com a comunidade. Os entrevistados 1, 2, 3, 4, 7, 8, 9, 16 e 17 colocam esta mudança, quando comparando com a primeira gestão, em que a comunidade foi mais envolvida nos processos de gestão da UC.

Em relação à comunidade, destaque para a relação com os pescadores, por serem beneficiários diretos da área em função da pesca. Esta relação nasce na primeira gestão e tem continuidade nesta gestão também.

\subsubsection{Outros destaques}

Um projeto de destaque neste período foi "Nosso rio tá pra peixe", com a participação da ESEC Carijós com o IC. O projeto teve como objetivo principal a pesquisa sobre conhecimento local dos peixes e analisou as condições da bacia hidrográfica e da pesca e coleta de campo em áreas dentro e fora da ESEC Carijós (Frey, 2009).

\begin{abstract}
Acho que um dos pontos marcantes do meu modo de ver que a ESEC contribuiu muito foi o projeto "Rio Vivo, Rio Morto" 22 foram dois anos de pesquisa dentro do Rio Ratones, [...] E lá dentro da ESEC a gente começou a ver como a gente ia fazer por onde. Começamos a discutir em 2005, mas conseguimos fazer em 2008, que a gente conseguiu efetivar o projeto e fazer dois anos de estudo (Entrevistado 2).
\end{abstract}

\footnotetext{
1841 anos, masculino, não nascido, residente na área de influência da ESEC Carijós.

1942 anos, masculino, nascido e residente na área de influência da ESEC Carijós.

${ }^{20} 30$ anos, feminina, não nascida, residente na área de influência da ESEC Carijós.

${ }^{21} 59$ anos, masculino, não nascido, residente na área de influência da ESEC Carijós.

${ }^{22}$ Vídeo que foi desenvolvido pela associação de Moradores e de Pescadores de Ratones dentro do projeto "Nosso Rio tá pra Peixe” (Frey, 2009).
} 
4.4. Terceiro período (2011 - 2016) Terceira Gestão da ESEC Carijós

O Gestor 3 assume a ESEC Carijós entre os anos de 2011 - 2016, marcando a terceira gestão citada nas entrevistas, que ocorreu na ESEC Carijós desde de sua criação.

\subsubsection{Estrutura}

O Gestor 3 investe em melhorias estruturais, como reforma do prédio e organização da parte administrativa. Mais uma vez fica evidente a precariedade do apoio do órgão responsável pela gestão da ESEC Carijós, neste caso em relação à estrutura.

[...] nestes 5 anos que fiquei, a maior parte da energia foi gasta, [...] foi neste prédio aqui. Até quando eu construi em 2011 [...], eu tinha apoio institucional. Foi o último apoio que tive do ICMBio em 2012 [...] (Entrevistado 12) $)^{23}$.

O Gestor 3 também foca em estruturar trilhas para ações internas de educação ambiental e, mais uma vez, é colocada a falta de apoio institucional.

Esta foi uma iniciativa minha. Eu fiz as trilhas, não tinha ninguém para me apoiar, mesmo sendo chefe. Eu via que precisava de um apoio externo. Tentei contratar pela compensação ambiental e não deu certo. E então fomos atrás de parceiros (Entrevistado 12).

\subsubsection{Gestão}

Esta Gestão se destaca pelo trabalho técnico, voltado para questões internas, como reformas estruturais e ações de educação ambiental dentro da ESEC Carijós. Externamente, o principal foco é a fiscalização. Segundo o Gestor 3, esta ação foi e continua sendo fundamental para controlar a pesca ilegal, assunto polêmico e desafiador. A relação com os pescadores continua sendo positiva, principalmente para os que vivem no entorno da UC e desejam também a proteção do Rio Ratones e seu entorno (Entrevistados 2 e 3). De outro lado, há uma crítica em relação à fiscalização excessiva e à falta de diálogo com a comunidade (Entrevistados 11 e 12).

\subsubsection{Educação ambiental e participação comunitária}

Com interesse e conhecimento na área, o Gestor 3 desenvolve ações de educação ambiental na sede da UC, por meio de trilhas no manguezal e restinga, mas este trabalho aparece somente na fala dos entrevistados envolvidos com este projeto (Entrevistados 7, 12 e 15), mostrando não conseguir abranger um público muito expressivo, principalmente a comunidade de entorno. Já não havia o apoio do IC neste período, já que é solicitada a saída do mesmo da sede da ESEC Carijós, levando ao desligamento oficial em 2012. Importante registrar a falta de olhar do ICMBio para as ações de Educação Ambiental (Entrevistado 12) e o entendimento da comunidade em relação ao trabalho desenvolvido, mesmo sem ações diretas de EA com a mesma (Entrevistado 9).

\footnotetext{
${ }^{23} 41$ anos, masculino, não nascido, residente na área de influência da ESEC Carijós.
} 
Em 2015 é formalizada uma parceria com a ONG Guardiões do Mar, com o projeto Uça. Segundo os entrevistados 7 e 12, este projeto surge como um importante parceiro para alavancar os movimentos de educação ambiental que estavam ocorrendo dentro da Unidade. A parceria ocorreu de março de 2015 a junho de 2016.

O Gestor 3 também é exonerado em 2016, deixando novamente um clima de insatisfação, principalmente da equipe interna e dos pescadores.

\section{Discussão}

Este trabalho foi proposto no sentido de identificar e avaliar as condições de governança de uma UC, tendo como elementos principais a educação ambiental, a gestão e a estrutura local. O resultado da pesquisa demonstra alguns resultados importantes a serem considerados. O primeiro, e que fica bem evidente, é o movimento político-administrativo do tipo top-down, desde a criação da UC até as escolhas

TABELA 1 - Resumo dos resultados.

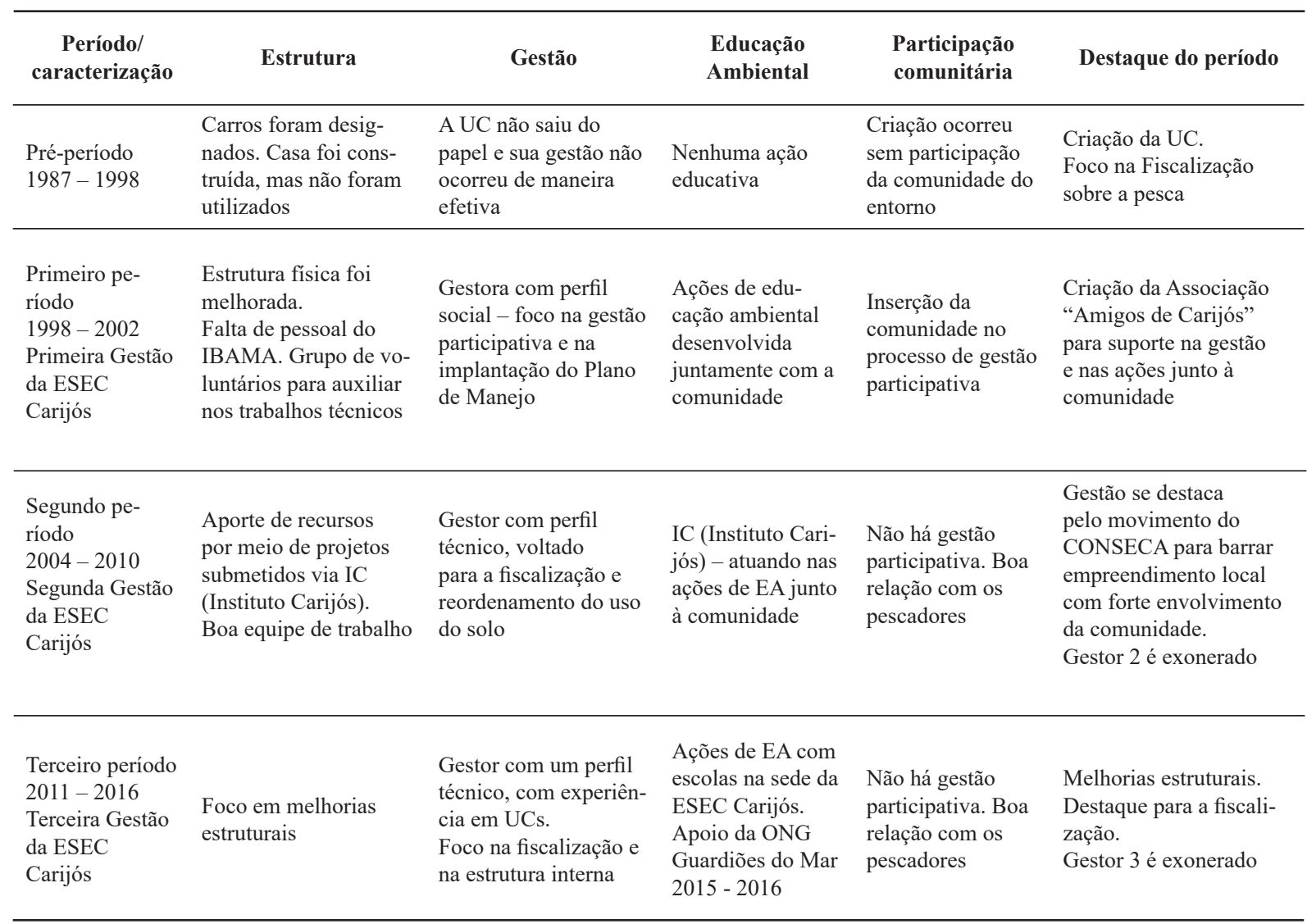

FONTE: elaboração própria baseada nas entrevistas e na pesquisa bibliográfica. 
dos gestores e suas tomadas de decisões. Isto fica claro no caso da ESEC Carijós, mas sabe-se que este não é um caso isolado na criação e na gestão das UCs no Brasil e em outros locais no mundo.

A estrutura da Unidade se mostra ineficiente desde a sua criação, tanto com relação à estrutura física como à de pessoal. Nota-se que a Associação "Amigos de Carijós" intitula em 2005 Instituto Carijós se destaca ao longo da história da ESEC Carijós em projetos de educação ambiental, aporte de recursos para a UC, melhorias estruturais, plano de manejo com participação da comunidade e demandas administrativas. Fica evidente a necessidade de uma melhor gestão dos recursos nesta UC. Os gestores não são escolhidos pela necessidade da Unidade, muito menos pelo perfil ou anseio da comunidade. A ESEC Carijós é marcada por três principais gestões com perfis diferentes, sem uma preocupação com a continuidade das ações de cada gestão, principalmente junto à comunidade, enfraquecendo a relação com a mesma e dificultando os processos de ações do gestor, tanto com o público interno quanto com o externo. As ações do gestor não são alinhadas de uma gestão para a outra, principalmente as ações de continuidade da primeira para a segunda gestão, destacando-se o fato de haver intervalos com gestores interinos neste período. Não há uma preocupação do órgão responsável pela UC em definir um profissional que seja designado para atuar na continuidade das ações. Ao contrário, parece que há um desinteresse em atender os interesses de uma maioria e, algumas vezes, até da própria gestão. Prova disto é a exoneração de dois gestores que estavam realizando, com base nas informações obtidas, um trabalho de acordo com os interesses da Unidade, sem argumento que pudesse justificar essa decisão. Particularmente, chama a atenção a exoneração do Gestor 2 que, conseguiu reunir no CONSECA pela primeira ver na histórico do Conselho, atores dos setores público e sociedade civil para busca da proteção dos ambientes naturais da região, incluindo a ESEC Carijós e seu entorno. Uma decisão que deve ser olhada com atenção, buscando refletir como pode-se reforçar um trabalho dentro de um espaço público de relevante interesse socioambiental e econômico, quando este tipo de ação não é levado em consideração e acaba por desconstruir um trabalho já realizado até o momento, sem argumentos que possam justificá-lo. Outro ponto que deve ser enfatizado foi a dificuldade de manter o Conselho Gestor que, mesmo sendo consultivo, é uma importante ferramenta de Governança, com foco na gestão participativa junto à UC.

Em relação às ações de educação ambiental e à participação comunitária, percebe-se que estas não são uma prioridade para o órgão regulador das UCs. Dentre as diretrizes do SNUC, que regulamenta as UCs no Brasil, podem ser destacadas as diretrizes II e III, que visam assegurar o envolvimento da sociedade e a participação das comunidades nos processos de tomadas de decisões em UCs (IBAMA, 2001). Apesar destas diretrizes, não há um caminho que possa nortear como isto deve ocorrer, nem tampouco muitos exemplos práticos neste sentido. Em relação à ESEC Carijós, as ações de gestão participativa ocorreram principalmente na primeira gestão, sendo raros ou até inexistentes nas demais gestões. A gestão participativa apenas ocorreu em um momento oportuno da história, no qual o tema estava na linha de frente de grandes eventos sobre parques na América latina24242424 e no mundo. Também influenciou o perfil social da Gestora 1, que assume a UC neste momento e não 
por exigência, apoio ou interesse do órgão regulador das UCs no Brasil.

Importante ainda frisar que esta ação junto à comunidade não seria possível sem a participação do terceiro setor, responsável por grande parte das ações de educação ambiental e pelo envolvimento da comunidade nos processos de gestão participativa. A Associação "Amigos de Carijós", posteriormente denominada Instituto Carijós, grupo do terceiro setor que atuou por mais de 10 anos junto à Unidade, foi o aporte necessário para suprir a falta de pessoal para desenvolver projetos de educação ambiental e gestão participativa junto à comunidade.

\section{Conclusão}

Partindo-se do pressuposto de que uma boa governança pode ser definida como um sistema complexo de interações, com foco no bem-estar humano, na educação ambiental e na gestão participativa, percebe-se que há um longo caminho a ser percorrido nos processos de gestão dentro de uma UC. Mais do que isto, há evidências claras que este tripé não atua com autonomia. Há um componente complexo e subjetivo que dá as diretrizes para este processo a ser percorrido, na forma de decisões políticas não facilmente mensuradas e não alinhadas às necessidades que surgem nestes espaços de gestão. Tais decisões são tomadas sem a participação da comunidade diretamente afetada e sem a necessária interferência participativa, como deveria ocorrer efetivamente. Esta evidência demonstra que este contexto necessita ser abordado de maneira mais profunda, buscando discutir sua implicação nos processos de governança em UCs. Ele parece inter- ferir e modificar o rumo dos processos para alcançar uma boa governança. Fica evidente, portanto, que, frequentemente, a realidade de uma $\mathrm{UC}$, não é levada em consideração nos processos de gestão, desde a escolha do gestor até a continuidade de suas ações. É igualmente evidente que os processos de inserção da comunidade por meio da construção participativa são fundamentais. As UCs são bens públicos e devem exercer sua função de servir à sociedade e com a sociedade. Só por meio deste processo é que os atores interessados poderão efetivamente compreender sua relevância e participar do processo de conservação da mesma. Enquanto houver um distanciamento entre UC e seu entorno, entre os tomadores de decisão e os que estão na linha de frente destas Unidades, os conflitos estarão se sobrepondo às necessidades, tanto de conservação dos ambientes naturais como das necessidades de pessoas que vivem nestes locais.

\section{Agradecimentos}

Ao LAGECI - Laboratório de Gestão Costeira Integrada da Universidade Federal de Santa Catarina (apoio técnico e financeiro para eventos). Ao CNPq - Bolsa de estudo do doutorado. Aos entrevistados que se disponibilizaram a contribuir de forma valiosa para esta pesquisa.

\section{Referências}

Alberti, V. Histórias dentro da história. In: Pinsky, C. (Org.). Fontes históricas. São Paulo: Contexto, 2010. p. 155-202.

Barragán, M. J. Política, Gestión y Litoral: una nueva visión de la Gestión Integrada de àreas Litorales. Espanã: Tébar Flores, 2014. 
Borrini-Feyerabend, G. Governance of protected areas: innovations in the air... Policy Matters, Durbam: IUCN, 12, 92-101, 2003.

Caruso, M. M. O desmatamento da Ilha de Santa Catarina de 1500 aos dias atuais. Florianópolis : UFSC,1990.

Dick, E.; Danieli, M. A.; Zanini, A. M. Gestão participativa em Unidades de Conservação: uma experiência na Mata Atlântica. Rio do Sul: APREMAVI, 2012.

Brasil, Estatuto Associação de Amigos Pró Conservação da Estação Ecológica de Carijós, de 9 de junho de 1999. Florianópolis, 1999.

Fischer, D.; Torres, R. F.; Urban, T. Um rio perto daqui: lições aprendidas com o Grupo de Monitoramento da APA do Iraí. Curitiba: Mater Natura - Instituto de Estudos Ambientais, 2006.

Frey, L. Nosso rio tá pra peixe ajuda na revitalização de Rio, 2009. Disponível em: <https://amacaca.wordpress. com/2009/07/10/nosso-rio-ta-pra-peixe-ajuda-na-revitalizacao-de-rio $>$. Acesso em: abril de 2017.

Himes, A. H. Performance indicators in MPA management: Using questionnaires to analyze stakeholder preferences. University of Portsmouth, UK: Elsevier, 2007.

IBAMA - Instituto Brasileiro do Meio Ambiente. Plano de Manejo da Estação Ecológica de Carijós. Florianópolis: IBAMA, 2001.

Jones, P. J. S.; Qiu, W.; De Santo, E. M. Governing marine protected areas: Social-ecological resilience through institutional diversity. Marine Policy, 2013.
Junior, S. da S. et al. (Orgs). Conservação da Biodiversidade na Zona Costeira e Marinha de Santa Catarina. Florianópolis: Instituto Chico Mendes de Conservação da Biodiversidade, ICMBio, 2015.

Mccay, B. J.; Jones, P. J. S. Marine Protected Areas and the Governance of Marine Ecosystems and Fisheries. Conservation Biology, 25(6), 1130-1133, 2011.

Minayo, M. C. de S. O desafio do conhecimento. São Paulo, Rio de Janeiro: Abrasco, 1999.

Nguinguiri, J. C. Gouvernance des aires protégées - importance des «normes pratiques» de régulation de la gestion locale pour la faisabilité des réformes dans le Bassin du Congo. In: IUCN - Commision on Envirommental, Economic and Social Policy. Community, Empowerment for Conservation. Congo, 2003. p. 16-21.

Pomeroy, R. S.; Parks, J. E.; Watson, L. M. How is your MPA doing? A Guidebook of Natural and Social Indicators for Evaluating Marine Protected Area Management Effectiveness. Switzerland and Cambride, UK: IUCN, 2004.

Puz, H. A.; Béchaux, E.; Jenkins, C. Gouvernance et democratie locale dans les Parcs Naturels Régionaux de. In: IUCN - Commision on Envirommental, Economic and Social Policy. Community, Empowermente for Conservation. Durban: World Parks Congress, 2003. p. 225-237, 2003.

Tozzo, R. A.; Marchi, E. C. Unidades de Conservação no Brasil: uma visão conceitual, histórica e legislativa. Revista Meio Ambiente e Sustentabilidade, 6(3), 508-523, 2014. 